\title{
OPTIMIZING THE FERTILITY RATE OF SUGARCANE CROPS AT PRECISION AGRICULTURE USING THE FUZZY LOGIC METHOD
}

\author{
Achmad Arif Alfin $^{1}$ | Raden Venantius Hari Ginardi*2
}

\author{
${ }^{1}$ Departement of Business and Technology \\ Management, Institut Teknologi Sepuluh \\ Nopember, Surabaya, Indonesia \\ ${ }^{2}$ Department of Information Technology, \\ Institut Teknologi Sepuluh Nopember, \\ Surabaya, Indonesia

\section{Correspondence} \\ *Raden Venantius Hari Ginardi, Department \\ of Information Technology, Institut \\ Teknologi Sepuluh Nopember, Surabaya, \\ Indonesia. Email: hari@its.ac.id
}

\section{Present Address}

Gedung Perpustakaan ITS Lt. 6, Kampus ITS Sukolilo, Surabaya 60111, Indonesia

\begin{abstract}
Soil fertility has a significant role in the sugarcane plantation industry to maintain plant fertility to obtain optimal yield productivity. The management system used by farmers only based on practices and estimation can not determine the exact needs of water, lime, and fertilizers in each plant's area. Therefore, we need a system that can provide a reference for giving water volume, lime content, and fertilization according to the nutritional needs of sugarcane plants. This study aims to design a system that can provide recommendations for sugarcane needs based on soil nutrient content using the fuzzy logic method. This method's first step is the fuzzification process carried out on four types of data used as input parameters, namely soil moisture, soil $\mathrm{pH}$, plant phase, and nutrient content. The next step is choosing the relevant criteria from each assessment to get the best alternative. In the next stage, a membership function is created to estimate the following process and defuzzification process. The study found the value of cost efficiency, optimization of growth in stem height, and plant tillers. The resulting cost efficiency is $30.05 \%$ compared to the factory method. While the level of optimization of plant growth compared to the factory method, tillering growth increased $8 \%$, but the development of primary stem height was higher by $3 \%$.
\end{abstract}

\section{KEYWORDS:}

Defuzzification, Fuzzification, Irrigation, Soil Fertility

\section{1 | INTRODUCTION}

Nowadays, technology is growing rapidly, both in the agriculture sector and in the machinery industry. However, the distribution of technology is still not evenly distributed in several countries. That was caused by several things, such as costs that were still expensive, geographical conditions in certain areas, and human resources that are still not qualified. In Indonesia, where 
most of the population are farmers, especially the island of java, still managing their agricultural land traditionally. One of its primary commodities is sugarcane. Sugarcane is a plant that requires high management intensity, starting from the irrigation process, controlling soil $\mathrm{pH}$, to the fertilization process. The current problem is that farmers' management system is only based on practices and estimation, so it can not determine the exact needs of water, lime, and fertilizers in each plant's area. Besides, the effectiveness of giving water and fertilizer are very beneficial for the environtment ${ }^{[1]}$. This system is based on the concept of precision agriculture, involving the assessment of variables that affect soil fertility, such as the type and characteristics of soil and water content in the field ${ }^{[2]}$. Therefore, it is significant to assess soil fertility based on moisture, nutrient content, and soil $\mathrm{pH}^{3}$.

This study discusses the precision agriculture application to manage the fertilization process, maintaining moisture and soil $\mathrm{pH}$ systems in sugarcane farming using the fuzzy logic method. This research is expected to improve the cost-efficiency of agriculture, including irrigation, minimize the use of fertilizers and dolomite lime. This system uses six sensors as input variables, pH sensors, humidity sensors, and NPK (Nitrogen, Potassium, and Phosphorus) sensors. The sensors' data are processed using the fuzzy logic method to obtain evaluation criteria and determine the appropriate output, namely the time of watering plants, the dose of plant fertilizer, and the dose of dolomite lime.

Generally, the system uses integrated sensors, and measurements are not carried out directly on the land (using radio signal frequencies) to allow for a lot of interference. This study uses separate sensors that are placed directly on the ground according to the specified points. This is to minimize measurement errors and minimize costs if there is damage to the sensors.

\section{2 | PREVIOUS RESEARCHES}

From previous research on the same topic of using the Fuzzy Logic method in the agriculture industry, most of the research uses built-in sensors, but some used direct sensors for specific control like control soil humidity for sugarcane. In some studies, some focused on precision agriculture, especially in handling irrigation systems. One of them is irrigation management based on humidity conditions using the fuzzy method. That system uses a fuzzy method to set the humidity value at a specific set point. This system uses an integrated sensor, including temperature, rain, solar radiation, wind speed, evapotranspiration. The weakness of the systems requires an internet connection, so it is not suitable in remote areas. Besides, this study has not explicitly explained the type of plant used in this study. Other studies focus on sugarcane, but the research only focuses on the irrigation system. Other factors that affect sugarcane fertility have not been discussed. The application of precision agriculture has a very broad scope. Some studies utilize web-based management. The database facilitates the collection and storage of vast quantities of plant data from farmers. To help farmers determine appropriate actions around their land. However, farmers enter the land condition data manually, so the system is not optimal for the broad coverage of the land area and has different conditions ${ }^{44}[5]$.

\section{3 | MATERIAL AND METHOD}

This paper presents an optimation soil fertility rate of Sugarcane Crops using the fuzzy logic method. The system is designed to assist farmers in optimizing their agricultural products, specific to sugarcane farming. One of the success factors in this farm is based on soil fertility level influenced by water humidity and acid-base soil [6].

This system uses six sensors, Yl-69 soil moisture sensors, pH sensors, and nutrient sensors (Nitrogen, Potassium, and Phosphorus sensor). The sensors are located at a specific location based on the soil's nutrient content at the beginning measurement. Raspberry pi processes data from the sensor in realtime, then the data are used as input parameters. Then, the data are processed using the fuzzy algorithm method to obtain the assessment criteria for other membership functions are made to be used in the defuzzification process.

\section{1 | System Diagram}

The optimation soil fertility rate of sugarcane crops has three block diagrams, input, process, and output. The nutrient sensor was formed by the integration of the light detection system and light transmission system. The RaspberryPi was used to operate the detectors and received data from the sensors. It was also used liquid crystal display (LCD) control functions to manage the display. 


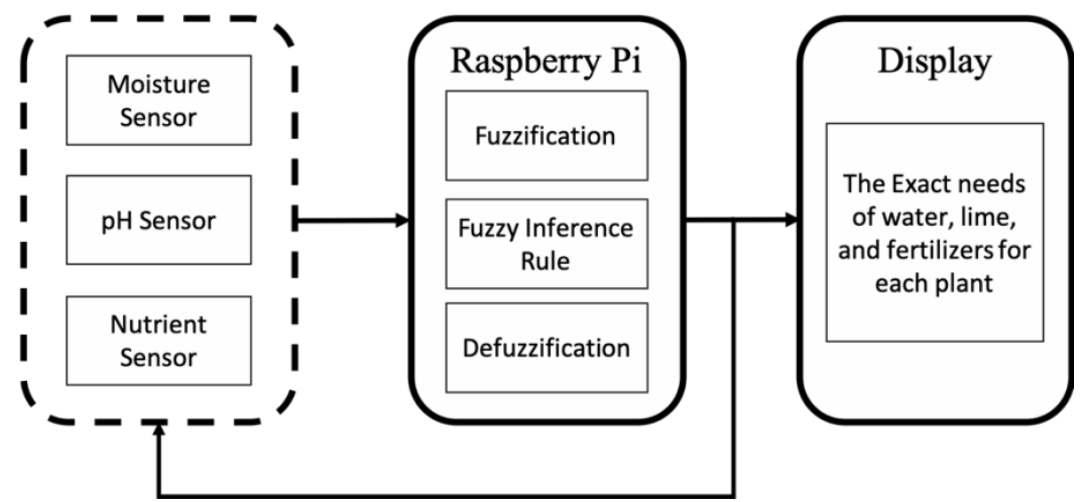

FIGURE 1 Block diagram of integrated monitoring and controlling system with raspberryPi.

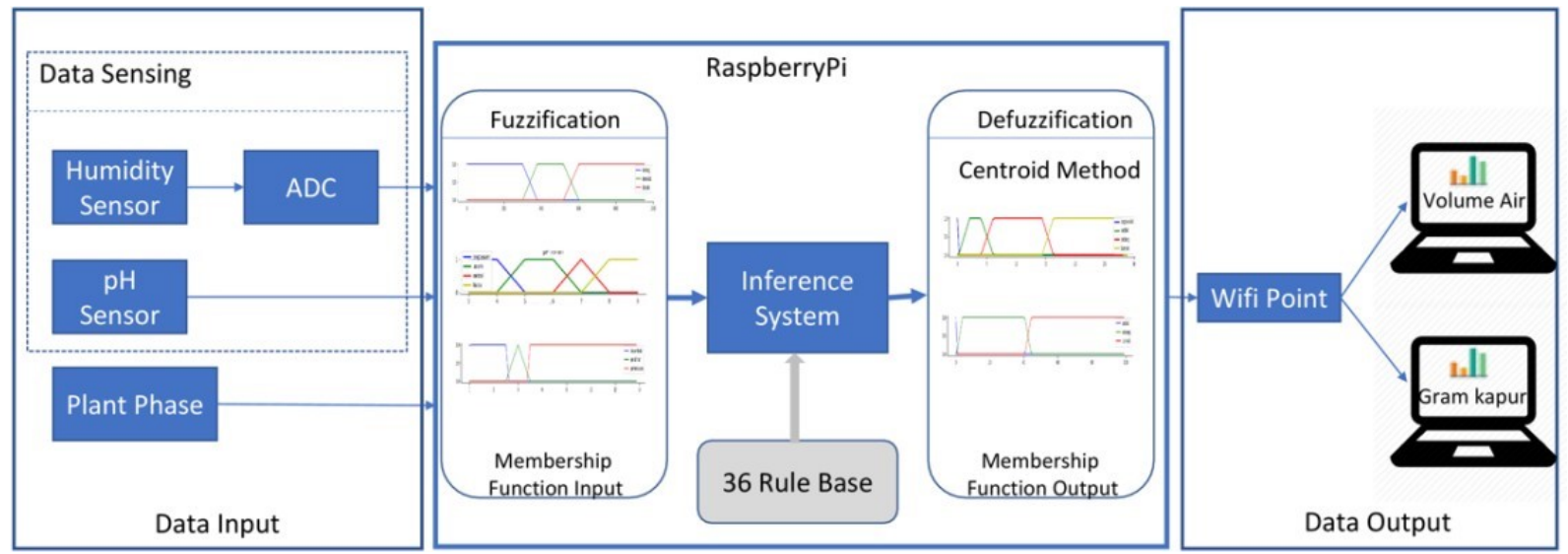

FIGURE 2 Schematic model for determining water needs and soil $\mathrm{pH}$.

The overview of the integrated monitoring and controlling fertility rate of sugarcane crops is illustrated in Fig 1 . This system is designed to provide recommendations automatically to farmers based on input data from sensors, namely humidity sensors, $\mathrm{pH}$ sensors, and soil nutrient sensors. The data is processed using the fuzzy logic method in raspberryPi. Output data from raspberryPi are recommendations that farmers must do to maintain their sugar cane plants' fertility. Besides, the output value is also displayed in realtime on the user's device to facilitate monitoring data.

\section{2 | Schematic model for Water Requirements and pH}

In Fig 2, all processes in the diagram are controlled via a computer using ssh. There are three types of input data in the diagram, one input is fixed and manually changed to input variables (plant phase), and the other is input data from the sensor, whose value changes according to soil conditions. Input data for soil conditions are sent to raspberryPi to be processed using the Fuzzy Logic method using the GPIO port. In general, there are three processes in fuzzy logic, i.e., fuzzification process to change input data (humidity, $\mathrm{pH}$, and plant phase) into fuzzy set data according to the type and form of the membership function.

\section{3 | Schematic model for Plant Nutrition}

The scheme in Fig 3 is a scheme for determining plant nutrition needs. The working principle of this method is not much different from diagram 4.10. The difference lies only in the input and data processing variables in fuzzy logic. The inputs are given to this model are the N, P, and K elements of the soil and the plant phase. The membership set used is as shown in Table $1-3$. This model uses 27 rule bases with three outputs, namely the needs of Urea, TSP, and Phonska fertilizers. Zone Management for sensor acquisition. 


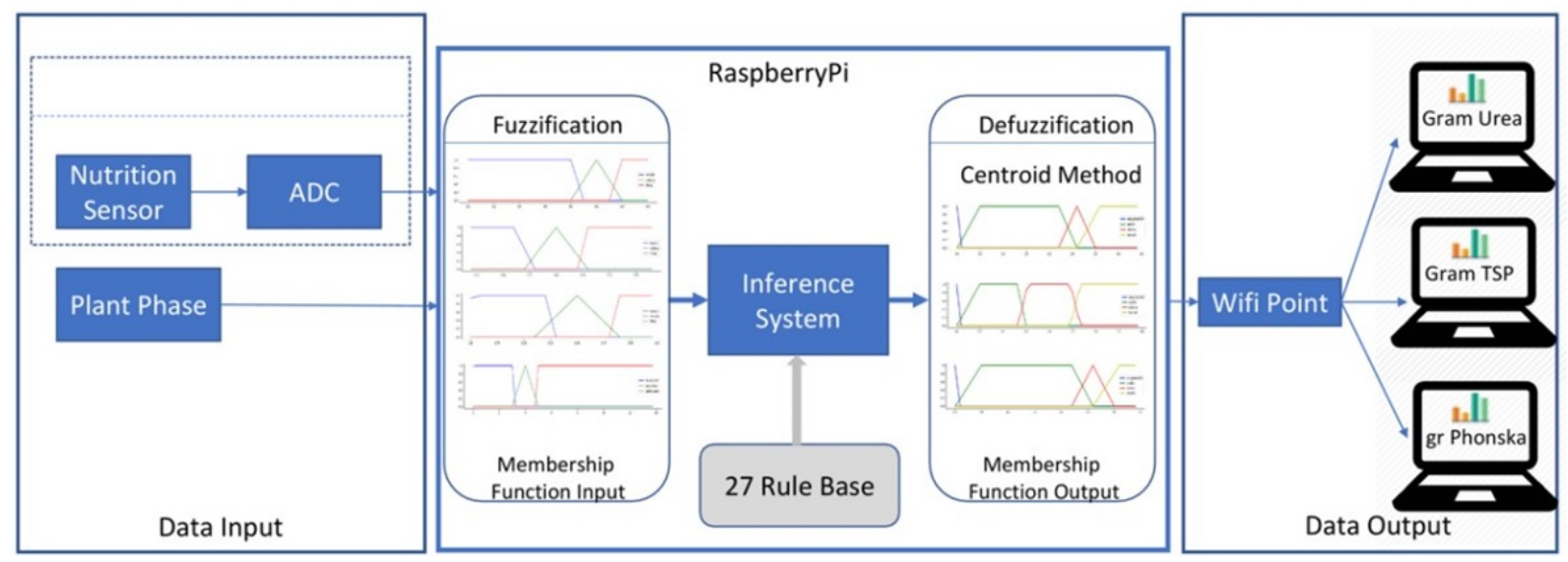

FIGURE 3 Schematic model for determining plant nutrition.

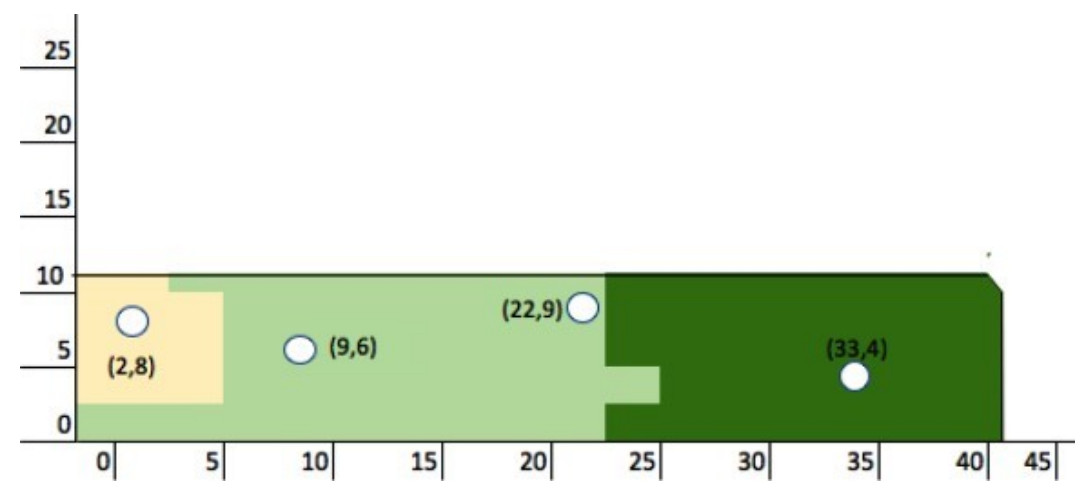

FIGURE 4 Distribution of sensor layout based on nutrient content, 1:100 scale.

\subsection{Management Zone for Sensor Acquisition}

The plotting sensor pattern is based on the identification of the diversity of measured soil content to improve the accuracy of soil fertility measurements ${ }^{[7}$. Based on the nature of the soil, which is the high content of groundwater and the texture of the soil, most of which influence the production of sugarcane. In Fig 4, The location of the sensor is based on the properties of the soil, which are at 4 points, namely the point (33.4), point (22.9), point (9.6), point (2,8) (Figure 4). In contrast, the measured variable is the daily data of soil moisture, plant nutrition, and soil $\mathrm{pH}$ calculated from the planting period to the maturity period.

\section{5 | Fuzzy Logic System}

The ability of fuzzy logic is to solve a problem related to precision. The fuzzy approach was used to weight attribute values. That was useful for investigating conditions whose value is between fraud and not fraud ${ }^{[8}$.

The main structure of this system can be seen in Fig 5. The initial step is to determine the membership function in the six input data and five output data, namely data on humidity, $\mathrm{pH}$, levels of N, P, and $\mathrm{K}$ soil, and plant age as input variables. In comparison, the output variables are water requirements, lime needs, Urea, TSP, and Phonska fertilizer needs. Input variables obtained from sensor input data are carried out periodically (once a week). Using raspberryPi Input variables obtained from sensor input data are carried out sometimes (once a week) using raspberry pi.

The next stage is input variable data from the acquisition of sensors into a fuzzy set following each membership's function. In a fuzzy system, there is a knowledge base that contains guidelines for the state of the system, which is used to obtain output according to the designer's wishes. The next process is translating fuzzy statements into rule-based mathematical calculations 


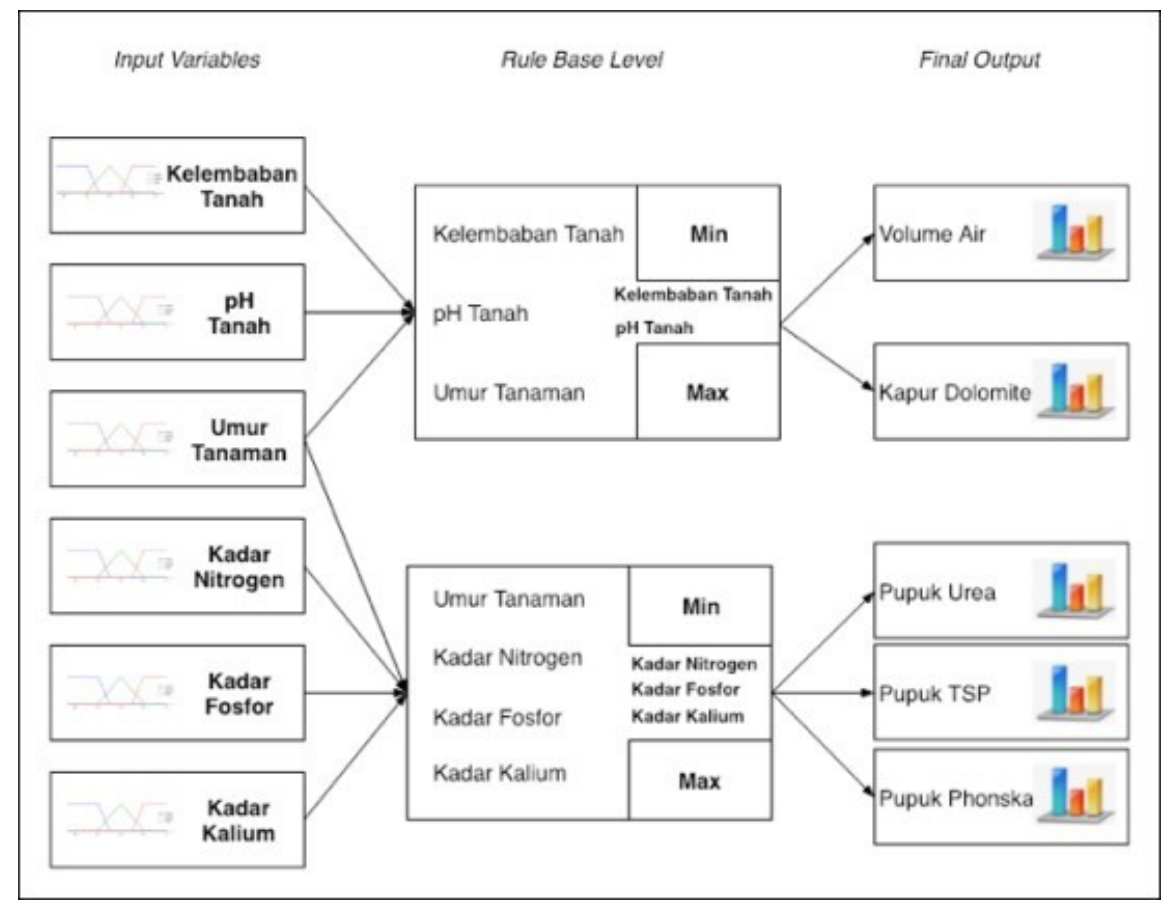

FIGURE 5 Main structure fuzzy rule set.

that function to determine the system's fuzzy rules. At the Fuzzy Inference System, the process of determining the dose of fertilizer, lime, and water volume values was carried out.

Defuzzification is the last step in the rules of a fuzzy logic system, where the output is a firm real number. In a designed system, it is useful to change each value from the results of inference to the form of value / real. This system's output is the volume of water, the level of fertilization, and the dose of lime in sugarcane.

\section{6 | Fuzzy Rule System for Controlling Soil Moisture and pH}

Fig 6 shows that control of the need for water and dolomite lime on fuzzy rules will be made using several parameters in sensor data output and plant life, like soil moisture, $\mathrm{pH}$, and plant phase. That Fuzzy rule is built based on the three sensor parameters described earlier. It can also be seen in the table that 36 rules will be implemented on recommendations for water and lime needs.

\section{7 | Fuzzy Rule System for Controlling Soil Nutrients}

The next design is the control of fertilizer levels based on the content of nitrogen, phosphorus, and potassium on the soil. In this study, the sensor's input parameters are soil nutrient levels (NPK Sensor) and plant age. The output given in this design is the amount of fertilizer needed in grams of plant clumps.

Fig 7 is a fuzzy rule of two variables used as input parameters. In the table, nine rules are implemented on the recommendation of fertilizing plants. A fuzzy rule is used for each soil nutrient measurement (NPK) so that there are a total of 27 rules for soil nutrient control.

\section{4 | RESULTS AND DISCUSSION}

The study was conducted starting from September 27, 2018, and ended on December 29, 2018. The object of the study used agricultural land with an area of $500 \mathrm{~m} 2$ compared to land with the same area with different treatments. The process of treating the comparison object was carried out according to farmers' habits in the area, so the authors only recorded data obtained from farmers for the quantity of fertilizer, lime, and nutrients used. While the selection of sampling for measuring plant height and 


\begin{tabular}{|c|c|c|c|c|c|c|c|c|c|c|c|c|c|c|c|c|c|c|c|c|c|c|c|c|c|}
\hline \multirow[t]{2}{*}{ No } & \multicolumn{3}{|c|}{ Moisture } & \multicolumn{3}{|c|}{ Phase } & \multicolumn{4}{|c|}{ Soil pH } & \multicolumn{2}{|c|}{ Output } & \multirow[t]{2}{*}{ NO } & \multicolumn{3}{|c|}{ Moisture } & \multicolumn{3}{|c|}{ Phase } & \multicolumn{4}{|c|}{ Soil pH } & \multicolumn{2}{|c|}{ Output } \\
\hline & $\mathbf{K}$ & $\mathbf{L}$ & B & $\mathbf{K}$ & PL & PT & SA & $\mathbf{A}$ & $\mathbf{N}$ & B & Water & Lime & & $\mathbf{K}$ & \begin{tabular}{l|l}
$\mathbf{L}$ & $\mathbf{1}$ \\
\end{tabular} & B & $\mathbf{K}$ & PL & PT & SA & $\mathbf{A}$ & $\mathbf{N}$ & B & Water & Lime \\
\hline 1 & & & & & & & & & & & Med. & Low & 19 & & & & & & & & & & & VLow & Med. \\
\hline 2 & & & & & & & & & & & High. & Low & 20 & & & & & & & & & & & VLow & High \\
\hline 3 & & & & & & & & & & & Med. & Med. & 21 & & & & & & & & & & & Med. & Low \\
\hline 4 & & & & & & & & & & & Med. & High & 22 & & & & & & & & & & & Med. & Low \\
\hline 5 & & & & & & & & & & & Med. & Low & 23 & & & & & & & & & & & Med. & Med. \\
\hline 6 & & & & & & & & & & & High & Low & 24 & & & & & & & & & & & Med. & High \\
\hline 7 & & & & & & & & & & & Med. & Med. & 25 & & & & & & & & & & & VLow & Low \\
\hline 8 & & & & & & & & & & & Med. & High & 26 & & & & & & & & & & & Low & Low \\
\hline 9 & & & & & & & & & & & High & Low & 27 & & & & & & & & & & & VLow & Med. \\
\hline 10 & & & & & & & & & & & High & Low & 28 & & & & & & & & & & & VLow & High \\
\hline 11 & & & & & & & & & & & High & Med. & 29 & & & & & & & & & & & VLow & Low \\
\hline 12 & & & & & & & & & & & High & High & 30 & & & & & & & & & & & Low & Low \\
\hline 13 & & & & & & & & & & & VLow & Sedikti & 31 & & & & & & & & & & & VLow & Med. \\
\hline 14 & & & & & & & & & & & Low & Low & 32 & & & & & & & & & & & VLow & High \\
\hline 15 & & & & & & & & & & & VLow & Med. & 33 & & & & & & & & & & & VLow & Low \\
\hline 16 & & & & & & & & & & & VLow & High & 34 & & & & & & & & & & & Low & Low \\
\hline 17 & & & & & & & & & & & VLow & Low & 35 & & & & & & & & & & & VLow & Med. \\
\hline 18 & & & & & & & & & & & Low & Low & 36 & & & & & & & & & & & VLow & High \\
\hline
\end{tabular}

FIGURE 6 Fuzzy rule system for controlling soil moisture and $\mathrm{pH}$.

\begin{tabular}{|c|c|c|c|c|c|c|c|}
\hline \multirow{2}{*}{ No } & \multicolumn{3}{|c|}{ Phase } & \multicolumn{3}{c|}{ Level of Soil Nutrient } & Output \\
\cline { 2 - 7 } & K & PL & PT & R & S & T & Fertility \\
\hline 1 & & & & & & & Low \\
\hline 2 & & & & & & & very low \\
\hline 3 & & & & & & & very low \\
\hline 4 & & & & & & & Medium \\
\hline 5 & & & & & & & very low \\
\hline 6 & & & & & & & very low \\
\hline 7 & & & & & & & High \\
\hline 8 & & & & & & & Medium \\
\hline 9 & & & & & & & very low \\
\hline
\end{tabular}

FIGURE 7 Fuzzy rule system for controlling soil nutrient.

number of tillers was made randomly by the author. System optimization testing is based on cost efficiency and estimation of the success of planting sugarcane. This is measured by the height of the stem and the number of tillers produced by sugar cane.

In Table 1, plants' needs are in 3 phases (Phases of sprouts, transitions, and germination). The table contains plants' total needs starting from water requirements, lime needs, and fertilizer needs. Besides, the table also includes the total costs in that phase. In calculating water requirements listed in the table, there are total needs in 1 land area of $500 \mathrm{~m} 2$. The cost of the table is the cost of bio-diesel fuel used. The absolute water requirement with the fuzzy method does not require up to 1 Liter of Bio Solar, because in practice, there is still fuel left over. The price used in detailing the cost of nutrition needs is the standard retail cost of subsidized fertilizers that farmers usually use. Based on the total cost details in table 4.15, it can be concluded that the level of efficiency of the use of fuzzy methods compared to the factory method is $37.09 \%$. Based on table 2, the author extrapolated 1 hectare of land, then the calculation of cost requirements was estimated as follows.

Figure 8 shows that the growth chart of plant height in the initial phase is better than the factory method. This is reasonable considering the consumption of factory fertilizer is focused on the early days. While graphs with fuzzy methods at the beginning of planting tend to be low growth. But towards the middle phase until the final phase of growth, growth continues to increase. This is possible because, in the initial phases, the consumption of fertilizers by plants tends to be small. Whereas in the final phase of planting, where plants need a lot of nutrients, nutritional needs with fuzzy methods are still sufficient compared to factory methods where the graph trend begins to decline. 
TABLE 1 Data comparison of plant efficiency.

\begin{tabular}{lllll}
\hline Parameter & Unit & $\begin{array}{c}\text { Fuzzy Method } \\
\text { Cost }\end{array}$ & Unit & $\begin{array}{c}\text { Factory Method } \\
\text { Cost }\end{array}$ \\
\hline Water Volume (L) & $18187 \mathrm{~L}$ & Rp. 5,150 & $66000 \mathrm{~L}$ & Rp. 10,300 \\
Lime Needs & 0 & Rp. 0 & 0 & Rp. 0 \\
Urea & $9.9 \mathrm{~kg}$ & Rp. 15,840 & $20 \mathrm{~kg}$ & Rp. 32,000 \\
TSP & $10.6 \mathrm{~kg}$ & Rp. 14,840 & $10 \mathrm{~kg}$ & Rp. 14,000 \\
Fonseka & $12.4 \mathrm{~kg}$ & Rp. 28,520 & $20 \mathrm{~kg}$ & Rp. 46,000 \\
Total & & Rp. 64,350 & & Rp. 92,000 \\
\hline
\end{tabular}

TABLE 2 Extrapolation of costs for plant care.

\begin{tabular}{lllll}
\hline Parameter & \multicolumn{2}{c}{ Fuzzy Method } & \multicolumn{2}{c}{ Factory Method } \\
& $500 m^{2}$ & $1 h a\left(10,000 m^{2}\right)$ & $500 m^{2}$ & $1 h a\left(10,000 m^{2}\right.$ \\
\hline Water Volume (L) & Rp. 5, 150 & Rp. 103,000 & Rp. 10,300 & Rp. 206,000 \\
Lime Needs & Rp. 0 & Rp. 0 & Rp. 0 & Rp. 0 \\
Urea & Rp. 15,840 & Rp. 316,800 & Rp. 32,000 & Rp. 640,000 \\
TSP & Rp. 14,840 & Rp. 296,800 & Rp. 14,000 & Rp. 280,000 \\
Phonska & Rp. 28,520 & Rp. 570,400 & Rp. 46,000 & Rp. 920,000 \\
Total & Rp. 64,350 & Rp. 1,287.000 & Rp. 92,000 & Rp. 2,046.000 \\
\hline
\end{tabular}

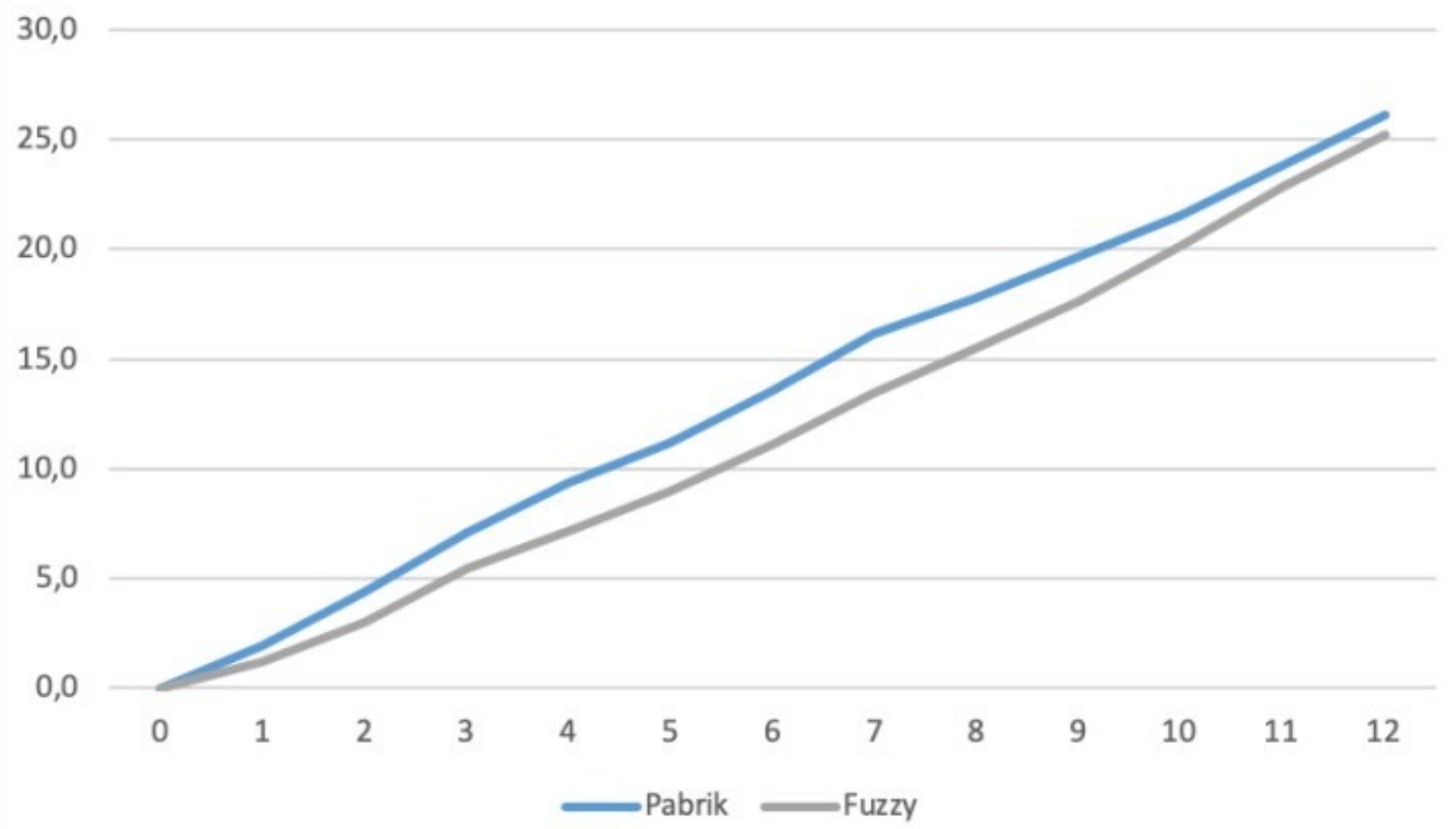

FIGURE 8 Plant growth chart $(\mathrm{cm})$.

In Figure 9, the breeding process in the initial phase is almost balanced with each other. However, starting on week 5, the factory method plants have a good average compared to the other methods. But the tendency of growing saplings is not as stable as with the factory method. This is possible for nutritional needs that are much needed during Peranakan during the sprouting period so that the nutrient content is not fulfilled.

Based on table III, it can be seen that the level of financing efficiency, when compared to the factory method, is more efficient using the fuzzy method. But for the level of optimization of growth, there is still better method from the factory. In addition to the optimization level, almost all assessments are still better using the fuzzy logic method. 


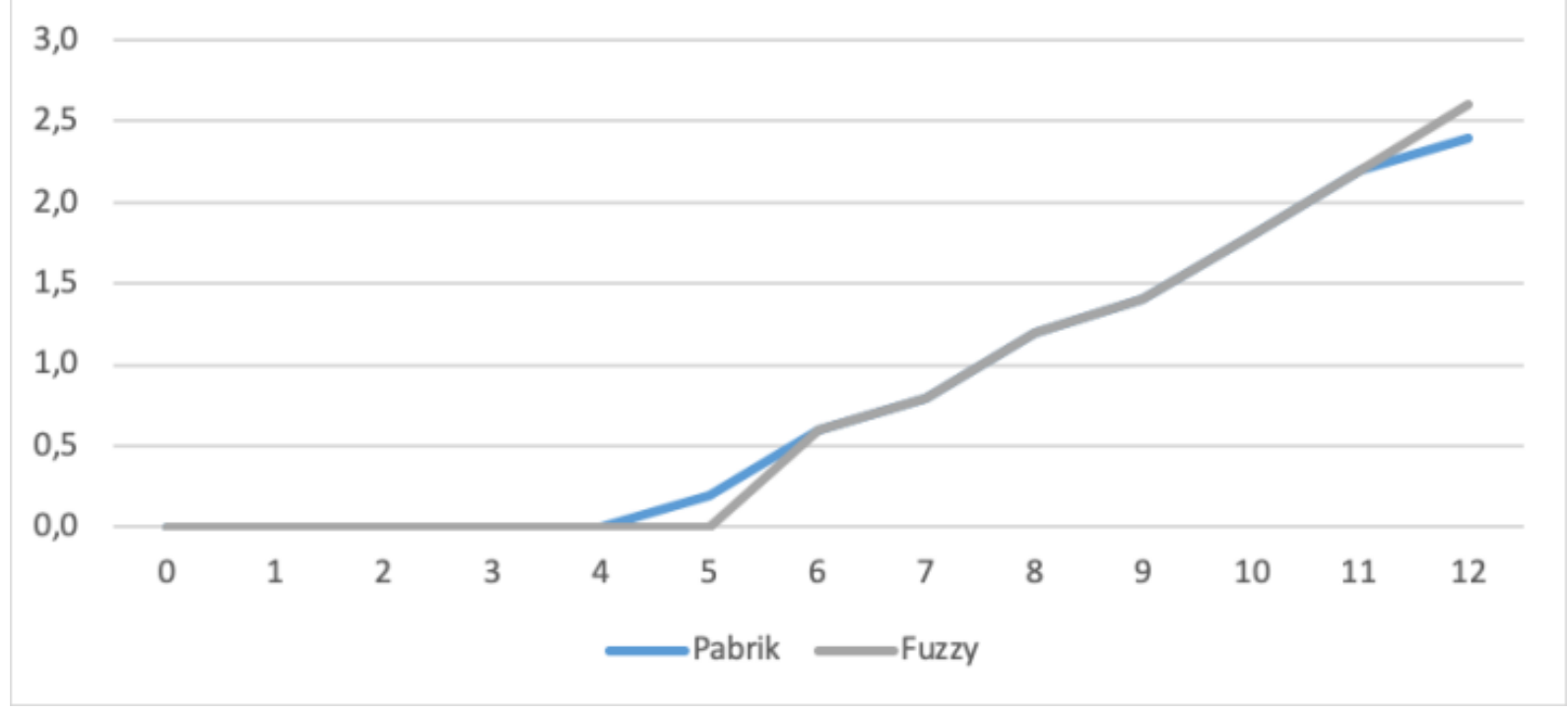

FIGURE 9 Plant seed growth chart.

TABLE 3 Comparison of fuzzy logic method with factory method.

\begin{tabular}{lccc}
\hline Method & Factory & Fuzzy & Percentage \\
\hline Cost $(\mathrm{Rp})$ & Rp. 92.000 & Rp. 64.350 & $37.09 \%$ \\
Stem height $(\mathrm{cm})$ & 26.1 & 25.2 & $3 \%$ \\
Tiller $($ Stem $)$ & 2.4 & 2.6 & $8 \%$ \\
\hline
\end{tabular}

\section{5 | CONCLUSION}

In conclusion, this model can determine plant nutrient requirements until the growth phase with the Fuzzy Logic method in the sugarcane management system can provide recommendations on the volume of water, fertilizer, and $\mathrm{pH}$ quite well. This is evidenced by the resulting cost efficiency of $37.09 \%$ and the excellent quality of tillers. It can also provide a level of optimization of tillers at $8 \%$. The rate of optimization of stem growth, despite decreasing by $3 \%$, but tends to be consistent in increasing stem growth compared to the factory method.

\section{6 | ACKNOWLEDGEMENT}

The authors gratefully acknowledge PG. Ngadirejo Kediri, where the research was conducted, and for their assistance in the field's research process until the evaluation process.

\section{References}

1. Gago J, Douthe C, Coopman RE, Gallego PP, Ribas-Carbo M, Flexas J, et al. UAVs challenge to assess water stress for sustainable agriculture. Agricultural Water Management 2015;153:9-19.

2. Lee WS, Ehsani R. Sensing systems for precision agriculture in Florida. Computers and Electronics in Agriculture 2015;112:2-9.

3. Zhang D, Guo P. Integrated agriculture water management optimization model for water saving potential analysis. Agricultural Water Management 2016;170:5-19. 
4. Srbinovska M, Gavrovski C, Dimcev V, Krkoleva A, Borozan V. Environmental parameters monitoring in precision agriculture using wireless sensor networks. Journal of Cleaner Production 2015;88:297-307.

5. Hanrahan L, Geoghegan A, O’Donovan M, Griffith V, Ruelle E, Wallace M, et al. PastureBase Ireland: A grassland decision support system and national database. Computers and Electronics in Agriculture 2017;136:193-201.

6. Daccache A, Knox JW, Weatherhead EK, Daneshkhah A, Hess TM. Implementing precision irrigation in a humid climate Recent experiences and on-going challenges. Agricultural Water Management 2015;147:135-143.

7. Serrano JM, Peça JO, Marques da Silva JR, Shaidian S. Mapping soil and pasture variability with an electromagnetic induction sensor. Computers and Electronics in Agriculture 2010;73(1):7-16.

8. Huda S, Sarno R, Ahmad T. Fuzzy MADM approach for rating of process-based fraud. Journal of ICT Research and Applications 2015;9(2):111-128.

How to cite this article: Alfin A.A., Raden Venantius Hari Ginardi R.V.H. (2020), Optimizing the Fertility Rate of Sugarcane Crops at Precision Agriculture Using the Fuzzy Logic Method, IPTEK The Journal of Technology and Science, 31(3):260-268. 